\title{
Experimental study of thermophysical properties of gasoline oil fractions
}

\author{
M. I. Chebotaryev and P. M. Kharchenko* \\ Kuban State Agrarian University named after I.T.Trubilin, Krasnodar, Russia
}

\begin{abstract}
Important physical properties, that characterize a substance, are the density and pressure of saturated vapors (PSV). These parameters need to be known when developing new technological processes in oil refining and chemical industries, designing pipelines, pumping equipment, fuel equipment, hydraulic cleaning processes, calculations related to the amount of petroleum products in mass volume, when operating technical systems running on liquid fuel. For gasoline fractions, the density is a normalized quality parameter, it is an integral part of various combined constants and calculation formulas.
\end{abstract}

\section{Purpose of work}

The aim of work is to study and develop experimentally the methods of calculating the density (specific volume) near and on saturation lines, as well as the pressure of saturated vapors of gasoline straight-run fractions, of different relative widths, obtained from oils of three fields: $110-120^{\circ} \mathrm{C}, 105-140^{\circ} \mathrm{C}$, NK- $180^{\circ} \mathrm{C}$ from Mangyshlak oil, NK-180 from Troitsko-Anastasyevskaya oil and NK-180 from the mixture of West Siberian oils when using liquid fuel in the agricultural complex.

\section{Main content of work}

One of the consumers of liquid fuel is the agro-industrial complex and transport of the country. In agriculture, almost all technological processes are carried out by machines and transport units, the main source of which is internal combustion engines. A significant part of the liquid fuel is purchased by agricultural producers, stored in warehouses of farms, and consumed according to technological necessity. Under these conditions, it is possible to reduce the quality of fuel, the deterioration of its heat and energy properties.

In addition, when the ambient temperature changes, the density of petroleum products changes, and, accordingly, their mass and volume, which leads to fluctuations in their cost and to increase in the cost of agricultural products produced.

An important factor determining the high requirements of the quality of petroleum products is the modern technical systems used in agriculture. These are usually energysaturated tractors, combines, self-propelled installations with complex and high-precision fuel devices that allow for low specific fuel consumption per unit of power. Their reliable

* Corresponding author: michebotarev@mail.ru 
operation is possible only with the required quality of petroleum products, especially in purity and density. The density, in some cases, helps to determine the chemical composition of the fuel. For example, if the measured density of gasoline is greater or less than the passport, then it can be argued that gasoline requires a detailed chemical analysis.

According to GOST, the density of fuel with an octane number from 91 to 98 is determined at a temperature of 15 and is $725-780 \frac{\mathrm{Kr}}{\mathrm{m}^{3}}$. The change in temperature leads to a change in density, which must be taken into account when determining the amount of oil products consumption. Determining the density of gasoline helps to find its mass in storage tanks in practice, if it is not possible to weigh it directly.

\section{Methodology of work implementation}

To determine the density of petroleum products in various conditions and situations, there was proposed the installation, the scheme of which was shown in Figure 1.

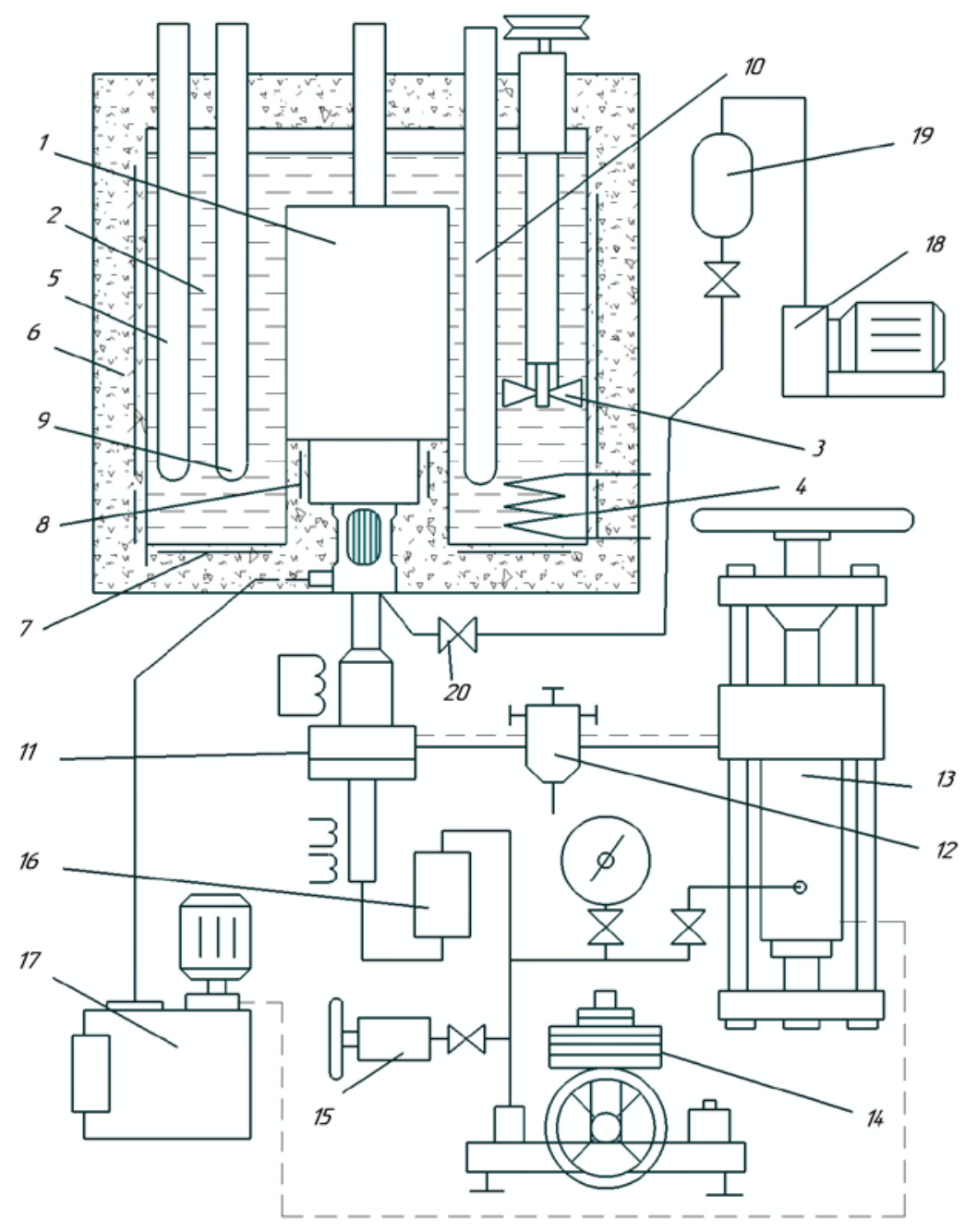

Fig. 1. Experimental setup 
The main element of the installation is a piezometer. The piezometer 1 is located in the liquid thermostat 2. Inside the piezometer is a solenoid-driven agitator and an exemplary platinum resistance thermometer. As a heat carrier, an organosilicon liquid PMS-100 is used, which allows working at temperatures from 20 to $320^{\circ} \mathrm{C}$. Mixing of the heat carrier in the thermostat is carried out with a stirrer 3 , cooling-with the help of a refrigerator 4 . The tubular heater 5 is used as a regulating one. Two main heaters 6 are wound around the thermostat shell.

There is a heater 7 in the bottom of the thermostat. To prevent heat outflows from the piezometer, a security heater 8 is used, wound on the piezometer stand. The outer surface of the thermostat is insulated with a layer of basalt wool.

The constant temperature in the thermostat is maintained by means of an automatic control system, the sensor of which is a regulating platinum resistance thermometer 9 . The temperature in the thermostat is measured by a model platinum resistance thermometer 10 of PTS-10 type of the $\mathrm{I}^{\text {st }}$ category according to the compensation scheme using a potentiometer P 363-2 of class 0.002 .

The piezometer communicates through the capillaries with the membrane separator II, which is the zero parameter of the pressure measurement system, the valve-distributor 12 and the volume meter 13 .

The pressure in the piezometer is measured by the compensation method with the 14-type MP-600, MP-60, MP-6 pressure gauges of the 0.05 class, and near and below the atmospheric pressure-with the spring pressure gauge and the vacuum gauge of the MO and VO type, respectively, of the 0.16 Class. At pressures below atmospheric pressure, a bellows pump 15 is connected to the measuring system.

To separate the oil of the cargo-piston pressure gauge from the water used as the working fluid in the zero indicator, a separator 16 is installed. The temperature of the volume meter, the valve-distributor, the zero indicator and all communications is maintained constant due to the circulation of water from the thermostat 17.

There is a vacuum pump 18, an expansion vessel 19 and a valve 20 for vacuuming and filling the piezometer with the test substance.

The created experimental setup makes it possible to measure the liquid density in the pressure range from 0.03 to $30 \mathrm{MPa}$ at temperatures of $20-320^{\circ} \mathrm{C}$ and the saturated vapor pressure using the static method and the method of studying isotherms.

\section{Results of research}

To calculate the density of oil fractions in the liquid phase, we used the Tate equation of the form:

$$
\vartheta_{\mathrm{T}, \mathrm{P}}=\vartheta_{\mathrm{T}, \mathrm{P}_{0}}\left[1-\mathrm{A} \ln \frac{B(T)+P}{B(T)+P_{0}}\right]
$$

The coefficient $A$ was assumed to be independent of temperature and the same for the entire group of substances, while B was a temperature function independent on pressure. The value of specific volume on the left boundary curve at a given temperature was taken as $\vartheta_{\mathrm{T}, \mathrm{P}_{0}}$ at $\mathrm{P}>\mathrm{P}_{\mathrm{aT}}$, and the value of specific volume at $\mathrm{t}=20$ and atmospheric pressure was taken as at $\mathrm{P}<\mathrm{P}_{\mathrm{aT}}$. The root-mean-square error of the density calculation was $0.3 \%$.

The analysis of dependences of the error in the description of the experimental data showed that at the given temperature, the error in the description lies within the error of the experimental data, and it increases to $0.7-0.8 \%$ in the near-critical region.

In the works of Rastorguev Yu. L., Grigoriev V. A., Shevchenko N. V., an equation of the form was used to generalize the temperature dependence of the coefficient B: 


$$
\mathrm{B}=\sum_{i=0}^{3} a_{i} c^{-i}
$$

The values of coefficients of equation (2) were found for gasoline fractions: $a_{0}=$ 41,4232; $a_{1}=-153,817 ; a_{2}=137,208$;

$$
a_{3}=27,9074 \text {. }
$$

For oil fractions by linear extrapolation to the high temperature range, it was previously found that $\mathrm{B}=0$ at $=0.91$. According to the data obtained in this work, a new value of $\mathrm{B}=0$ at $=0.925$ is determined. The description of the coefficient $B=f\left(\frac{1}{\tau}\right)$ showed increase in nonlinear nature of this dependence at $\tau>0,95$.

The pressure in the two-phase region depends on the temperature and the ratio of the phase volumes $\varphi=\frac{V_{n}}{V_{ж}}$. Lines of equal values $\varphi$ were allocated to find the analytical dependence of the pressure on these parameters on large-scale graphs in P-V coordinates. At $\tau<0,85$ the values $\varphi$ were calculated from the mass of liquid drained from the piezometer.

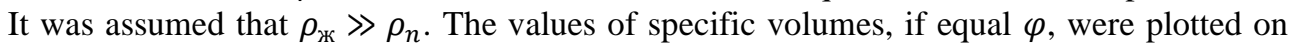
corresponding isotherms and connected by a smooth curve. Moreover, at $\tau>0,85$, the extrapolation of $\varphi$-const lines was carried out up to the critical point $\tau<0,85$ t.

Attempts have been made to generalize the pressure at different isotherms at corresponding values using various combinations of critical density (critical volume), critical pressure, and critical temperature as reduction parameters. The most successful is the description of pressure difference in the form of:

$$
\Delta \pi(\varphi)=f\left(\varphi ; \pi^{\prime}-\pi^{\prime \prime}\right)
$$

where

$$
\Delta \pi(\varphi)=\frac{\Delta P(\varphi)}{P^{\prime}-P^{\prime \prime}}
$$

$\Delta P(\varphi)$ - this is the pressure difference on the isotherm at the saturation point on the left boundary curve and the point with a certain value $\varphi$;

$$
\pi^{\prime}-\pi^{\prime \prime}=\frac{P^{\prime}-P^{\prime \prime}}{P_{\mathrm{Kp}}}
$$

A two-parameter equation of the form is obtained in the result of processing an array of 350 values:

$$
\ln \Delta \pi(\varphi)=\sum_{i=0}^{3} B_{i}(\ln \varphi)^{i}+\sum_{j=1}^{3} c_{j}\left(\ln \left(\pi^{\prime}-\pi^{\prime \prime}\right)\right)^{j} .
$$

Table 1. Coefficients of equation (6)

\begin{tabular}{|c|c|c|c|c|c|c|}
\hline$B_{0}$ & $B_{1}$ & $B_{2}$ & $B_{3}$ & $c_{1}$ & $c_{2}$ & $c_{3}$ \\
\hline 71,1959 & 0,456101 & 53,345 & $-0,0817$ & 12,5252 & 0,00493 & 0,98661 \\
\hline
\end{tabular}

The root-mean-square error of the description according to equation (6) is 3\%, which leads to a relative error in calculating the pressure in the two-phase region not exceeding $0.2 \%$. The values necessary for the calculation and are obtained as a result of analytical description of the dependence of reduced pressure on reduced temperature $(\pi-\tau)$ on the boundary curves. The analysis of graphical dependence $\pi-\tau$ for all fractions shows that the lines $\pi^{\prime}$ and $\pi^{\prime \prime}$ and are naturally stratified. The graphs $\pi^{\prime}-\tau$ and broad fractions $\pi^{\prime \prime}-\tau$ lie above the corresponding lines of narrower fractions. The difference $\pi^{\prime}-\pi^{\prime \prime}$ for all fractions varies as a function of $\tau$, monotonically increasing from almost zero at $\tau=0,5$, reaching a maximum at $0.85<\tau<0,90$ and then decreasing to 0 at $\tau=1$. 
The acentricity factor and various combinations of state parameters and physico-chemical characteristics were tested to find the parameters that allow describing the stratification. The best results were obtained when using the relative width of the fraction as a correlating parameter:

$$
\Delta \tau=\frac{T_{\text {Кк }}-T_{\text {н.к }}}{T_{\text {кр }}}
$$

Presumably, as a model of such a fraction, it is possible to test individual hydrocarbons that are close to studied fractions in terms of boiling point and critical temperature and pressure, a graphical check of the pressure dependence on the temperature of some individual hydrocarbons. It showed that they were significantly stratified with each other in coordinates. The points of the reference curve were described by equations used in the description of pressure from temperature for pure substances (the equation of Antuon, Kirchhoff, Riedel). However, there was a systematic deviation of curves described by these equations from the reference curve. Moreover, the deviations increased as they rose. Therefore, the values on the reference curve were described by the equation of the form of:

$$
\pi=A+B \tau+c \tau^{2}+D \tau^{3}+E \log \tau
$$

Where $A=-56,23787 ; B=116,70118 ; C=-93,837626 ; D=34,374218$

We calculated critical parameters of studied products using various methods, and found out that we used the Nokey formula used for calculating the critical temperatures of pure hydrocarbons in the form of:

$$
\log T_{c}=A+B \log S \cdot b+C \log T_{\mathrm{B}}
$$

The relative density of the product at $20^{\circ} \mathrm{C}$ and atmospheric pressure was used as the value $S \cdot b$, and the average volume of the boiling point of the oil product (K) was used as the value $T_{\mathrm{B}}$.

Table 2 shows the coefficients of equation (8) for calculating the critical parameters and the root-mean-square errors relative to the experimental values obtained in the work.

Table 2. Values of coefficients of the equation (8) and root-mean-square errors of the calculation

\begin{tabular}{|c|c|c|c|c|}
\hline $\begin{array}{c}\text { Critical } \\
\text { parameter }\end{array}$ & A & B & C & $\%$ \\
\hline$T_{\text {кр }}$ & 1,1004405 & 0,2498864 & 0,652894 & 0,13 \\
\hline$P_{\text {кр }}$ & 2,1121611 & 0,7964562 & 0,235387 & 3,60 \\
\hline$\rho_{\text {кр }}$ & 0,0483814 & 0,9286144 & $-0,213081$ & 0,04 \\
\hline
\end{tabular}

\section{Conclusions}

A method of calculating the density and pressure of saturated vapors of straight-run gasoline fractions has been developed, which allows experimentally determining their value and the quality of gasoline for compliance with requirements and specifications.

\section{References}

1. P.M. Kharchenko, V.P. Timofeev, Multidisciplinary network electronic scientific journal of KubSAU, Results of experimental researches of gasoline oil fractions (№ 98. P. 528543, 2014) Khristichenko

2. P.M. Kharchenko, V.P. Timofeev, Proceedings of KubSAU, Researches of oil fractions types (№39 P. 140-142,2012) 
3. P.M Kharchenko, V.V Khristichenko, N.A Bloshchinsky, Proceedings of KubSAU, Experimental installation and method of researches of density and for industrial waste waters (№ 37.P. 238-242, 2012).

4. P.M. Kharchenko, V.V. Khristichenko, A.A. Timofeev, Proceedings of KubSAU, Ventilation of production and municipal buildings (№ 37.P. 271-275., 2013).

5. P.M. Kharchenko, V.P. Timofeev, Proceedings of KubSAU, Calculation of ventilation and heating of production buildings (№ 42.P.152-155, 2013)

6. I.A. Потапенко, N.I. Bogatyrev, E.A. Adadurov, P.M. Kharchenko, D.Yu. Semernin, V.A. Grishaev, Method of thermal treatment of machine parts (Claim № 2005131682/02 from 12.10.2005, 20.04.2007.)

7. M.I. Chebotarev, P.M. Kharchenko, Proceedings of St. Petersburg State Agrarian University, Experimental setup for studying the density and pressure of saturated vapors of gasoline oil fractions (№ 57. P. 157-162, 2019) 